\title{
Functional responses of human and rabbit platelets induced by milk from indigenous Greek dairy goats (Capra prisca)
}

\author{
Dimitrios Peschos ${ }^{1}$, Yannis Simos ${ }^{1 *}$, George Fthenakis ${ }^{2}$, John Zelovitis ${ }^{1}$, Athina Boulaka ${ }^{1}$, Maria Giouli ${ }^{1}$, Elena \\ Georgiou $^{1}$, Vasilios Ragos ${ }^{3}$, Athina Tzora ${ }^{4}$, George Tsangaris ${ }^{5}$, Angelos Evangelou ${ }^{1}$, Spyridon Karkabounas ${ }^{1}$ \\ ${ }^{1}$ Laboratory of Physiology, School of Health Sciences, Department of Medicine, University of Ioannina, Greece. ${ }^{2}$ Obstetric Clinic of Small Animals, \\ School of Veterinary, University of Thessaly, Greece. ${ }^{3}$ Department of Maxillofacial Surgery, School of Health Sciences, Department of Medicine, \\ University of Ioannina, Greece. ${ }^{4}$ Department of Animal Reproduction TEI of Epirus, Greece. ${ }^{5}$ Biomedical Research Foundation of Athens Academy, \\ Greece.
}

\section{ARTICLE INFO \\ Article history: \\ Received on: $15 / 02 / 2016$ \\ Revised on: 03/03/2016 \\ Accepted on: 17/04/2016 \\ Available online: $28 / 05 / 2016$}

Key words:

Goats' milk; platelets;

thromboxane; ascorbic acid;

linolenic acid.

\begin{abstract}
The aim of this study was to investigate the biological properties of goat milk from the indigenous Greek breed (Capra prisca). The activity of the milk on platelet aggregation and thromboxane B2 (TXB2) production was evaluated on platelets isolated from blood obtained from both humans and rabbits. To further understand the biological properties of the milk ascorbic acid, linoleic and linolenic acid, were also tested. Ex vivo trials showed that milk from indigenous Greek dairy goats (Capra prisca) inhibited platelet aggregation at a dose dependent manner, both in humans and rabbits and decreased production of $\mathrm{TXB}_{2}$. The milk's ability to inhibit platelet aggregation and reduce $\mathrm{TXB}_{2}$ production could be attributed to its high content in antioxidant substances and poly-unsaturated fatty acids (such as ascorbic acid and linolenic acid), when originating from grazing goats in semi-mountainous shrublands. The paper provides information for nutritionists and health professionals, about the biological properties of specific types of milk and their potential use as functional foods.
\end{abstract}

\section{INTRODUCTION}

During the last 50 years it has become clear that several of the degenerative and infectious diseases in man, are greatly affected by the nutritional habits of individual populations over time. It has further been shown that the nutritional patterns that have been established in the Mediterranean basin over thousands of years exert a protective effect, concerning such diseases, on the population (Willett et al., 1995). Studies analysing the protective effect of the Mediterranean diet indicate that this diet contains large amounts of the necessary vitamins, trace elements, polyunsaturated fatty acids and poly-phenols; all these substances have a high anti-oxidative potential and function as detoxifiers modifying the immune mechanisms of the organism, reduce the intense proinflammatory reactions and function towards

\footnotetext{
* Corresponding Author

Yannis V Simos, Laboratory of Physiology, School of Health Sciences, Department of Medicine, University of Ioannina, Greece

Email:simosyannis@gmail.com
}

normalising the metabolism of individual cells and tissues (Martinez-Gonzalez and Sanchez-Villegas, 2000; Pitsavos et al., 2005). In recent years, on the subject-matter of milk, it has been shown that goat milk contains a wealth of anti-oxidative factors (Kondyli et al., 2007).

Specific anti-oxidant factors, such as vitamins $\mathrm{C}$ and $\mathrm{E}$, found in high concentrations in goat's milk, exert alone or in combination, anti-tumorous and anti-platelet actions (Kallistratos et al., 1988; Kallistratos et al., 1994; Evangelou et al., 1997; Sofis et al., 1994; Karkabounas et al., 1996). It has also been found that goat milk, just like donkey milk, possess interesting nutritional and bio-functional properties, that are related to the genetic characteristics of the herds to which the specific animals belong (Tafaro et al., 2007; Jirillo et al., 2010; Amati et al., 2010; D'Alessandro et al., 2010). Goat milk and its respective dairy products have an important place in human nutrition; in addition, it is considered an important food, especially for children, as it can fully substitute cow's milk (Hanlein, 2001). 
Goat milk differs from that of other species presenting enhanced fat digestibility due to the presence of lipid globules of small size (Attaie and Richter, 2000), composed mostly of shortchain fatty acids (Hachelaf et al., 1993; Alonso et al., 1999).In a relatively recent study it has been shown that the daily provision of goat milk for a period of one month in a group of healthy aged subjects seems to reduce the exaggerated acute phase response, as it was recorded by the dramatic decrease of the cytokine IL- 8 (Amati et al., 2010). Casein macropeptides from caprine milk has shown to posses similar antithrombotic properties to those of $\gamma$ fibrinogen 400-411 peptide (Qian et al., 1995; Manso et al., 2002). Simos et al., 2011 have recently showed that that cow's and goat's milk possess considerable inhibitory ability regarding platelet aggregation, an ability that is well-correlated to their total antioxidant strength. Based on these data we embarked on a study of the ability of goat milk from Capra prisca, a Greek indigenous herd, to inhibit human platelet ex vivo and washed rabbit platelet aggregation in vitro, as well as to inhibit in parallel the production of $\mathrm{TXB}_{2}$ from human platelets. In these same experiments we also studied the action of ascorbic acid, linoleic and linolenic acid on the various experimental settings used.

\section{MATERIALS AND METHODS}

\section{Volunteer blood donors}

Ten healthy volunteers ( 5 male and 5 female), between 26 and 52 years of age (mean age $29 \pm 10$ y) were enrolled in this study. The participation of the volunteers in the study was without monetary compensation and in agreement with the human rights legislation from the Declaration of Helsinki (1979). The volunteers were free of medical problems in their history. Moreover, they did not consume any kind of medication or food supplements, and did not consume alcoholic drinks during the experiment.

\section{Experimental animals}

Twelve male New Zealand white rabbits were used for the study, weighing 4-6 kg. The animals were housed in a modern animal house, with a constant light period of $12 \mathrm{hrs}$, and were kept in large cages that allowed communication among the animals. Access to food and water were ad libitum. The animals were fed a special feed mixture for rabbits (New Zealand White rabbits), and were daily supplied with fresh vegetables, in order to achieve a balanced diet. Blood (about 30-40 mL) was withdrawn from their ear veins via free blood flow.

\section{Preparation of human platelets}

The preparation of human platelets for the ex vivo experiments of platelet aggregation was performed according to Simos et al., 2011. Briefly, blood was taken from the medial cubital vein by free flow with the aid of an appropriate needle. The blood was placed in test tubes containing citric acid as anticoagulant agent in the proportion $1 \mathrm{~mL}$ of anticoagulant solution to $9 \mathrm{~mL}$ of blood and was gently mixed by end-over-end mild rotations. Centrifugation of the blood samples was performed at $54 \mathrm{x} \mathrm{g}$ for $20 \mathrm{~min}$ in order to separate the plasma rich in platelets (PRP) fraction. The PRP is then transferred to a plastic centrifuge tube, capped and remains in a water bath of $37^{\circ} \mathrm{C}$ until the end of the experiment. The test tubes containing the rest of the blood were centrifuged again at $645 \mathrm{x} \mathrm{g}$ for $20 \mathrm{~min}$ to isolate the plasma poor in platelets (PPP) fraction, which was collected in a plastic tube and used for calibration of the aggregometer.

\section{Preparation of washed rabbit platelets}

The procedure was described in details by Evangelou et al., 1998. Briefly, after separation of PRP according to the procedure described above, the tube is centrifuged, the supernatant was discarded and an equal volume of buffer solution ( $\mathrm{pH}$ 6.5) was added. The solution was gently mixed with the use of a pipette. The same procedure (centrifugation and mix of platelets) was repeated once more. Platelets were then counted and their number was fixed at 250.000 cells $/ \mu \mathrm{L}$ before the addition of the platelet agonists (adenosine diphosphate, ADP; platelet activating factor, PAF and arachidonic acid, ARA).

\section{Platelet aggregation experiments}

All assays for platelet aggregation and platelet reactions (shape changes and release reaction) were conducted on the aggregometer. For every aggregation test, samples were placed in a cuvette, containing $450 \mu \mathrm{L}$ of PRP and $50 \mu \mathrm{L}$ of each of three diluted platelet agonists (ADP, PAF and ARA) in $\mathrm{ddH}_{2} \mathrm{O}$. Goat milk at different doses $(2.5,5.0,10.0$ and $20.0 \mu \mathrm{L})$ was diluted in $50 \mu \mathrm{L}$ of $\mathrm{ddH}_{2} \mathrm{O}$ and incubated for 5 minutes in a cuvette containing $450 \mu \mathrm{L}$ PRP. Each of the three agonists was then added and the percentage of platelet aggregation was recorded at the aggregometer. All experiments were performed in triplicates.

\section{Platelet $\mathrm{TXB}_{2}$ production}

For the estimation of thromboxane $\mathrm{B}_{2}$ production in PRP the assay kit $\left.\mathrm{TXB}_{2} / 2,3-\mathrm{DINOR}-\mathrm{TXB}_{2}{ }^{125}\right]$ radioimmune assay KIT (Isotop company, Institute of Isotops Co. Ltd. Budapest, Hungary) was used. Thromboxane $\mathrm{B}_{2}$ production was estimated in PRP before platelet aggregation and $5 \mathrm{~min}$ after its initiation, with and without incubation with the goat milk at the above mentioned doses. After the completion of platelet aggregation $1.25 \mathrm{mg}$ of indomethacin was added to the samples (to inhibit $\mathrm{TXB}_{2}$ production by the arachidonic acid pathway enzymes) and the samples were centrifuged at $2500 \mathrm{x} \mathrm{g}$ for $5 \mathrm{~min}$ and supernatant was collected. Radioactivity of each sample was measured by $\gamma$ counter and the result was expressed in $\mathrm{pg} \mathrm{TXB}_{2} / \mathrm{mL}$.

\section{Statistical analysis}

Values are expressed as the mean $( \pm \mathrm{SD})$ shown as a percentage, compared to the platelet aggregation values and the $\mathrm{TXB}_{2}$ values in untreated (only with an agonist) platelets (100\%). All statistical procedures were performed using SPSS (SPSS 16.0, SPSS Inc. Chicago, Illinois, USA, 2009). The statistical significance between data means was determined by using paired sample t-test. Data are expressed as mean \pm SD. 

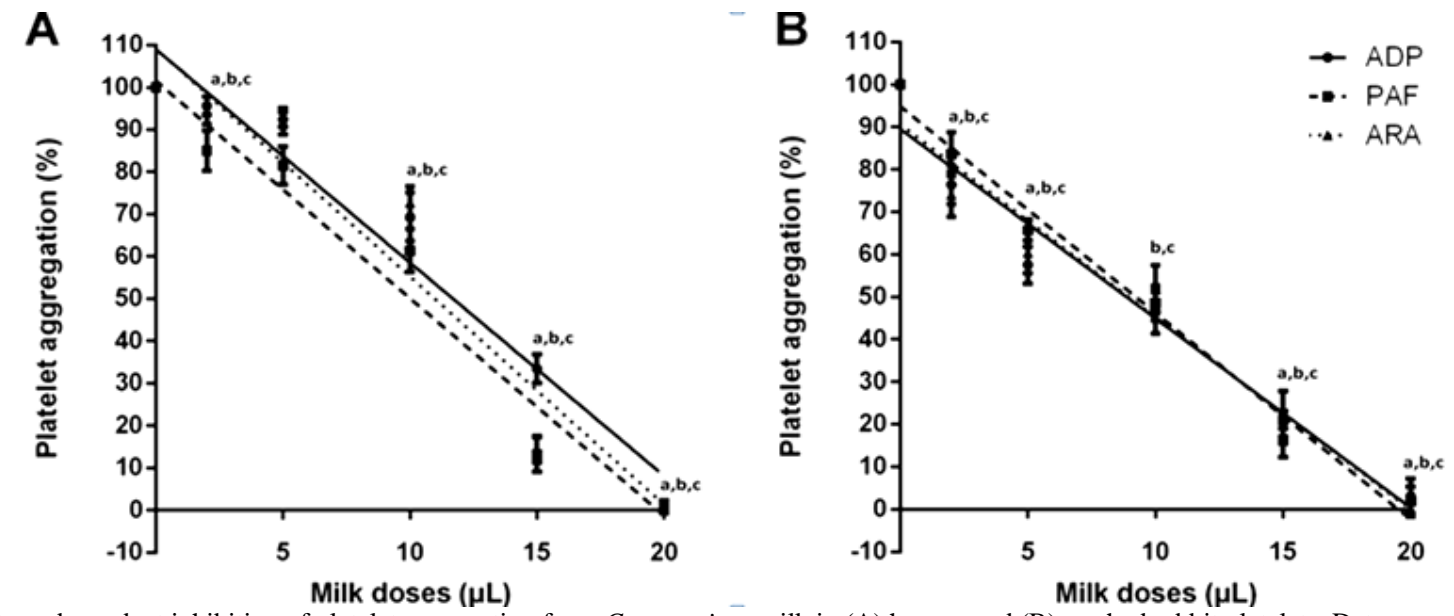

Fig. 1: Dose-dependent inhibition of platelet aggregation from Capra prisca milk in (A) human and (B) washed rabbit platelets. Data are expressed as mean \pm S.D. Each test was performed in triplicates. ADP, adenosine diphosphate; PAF, Platelet activating factor; ARA, arachidonic acid. Different letters indicate the significant differences $(\mathrm{p}<0.05)$ among the current and the exact previous (lower) dose. Symbol a for ADP, $b$ for PAF and $c$ for ARA
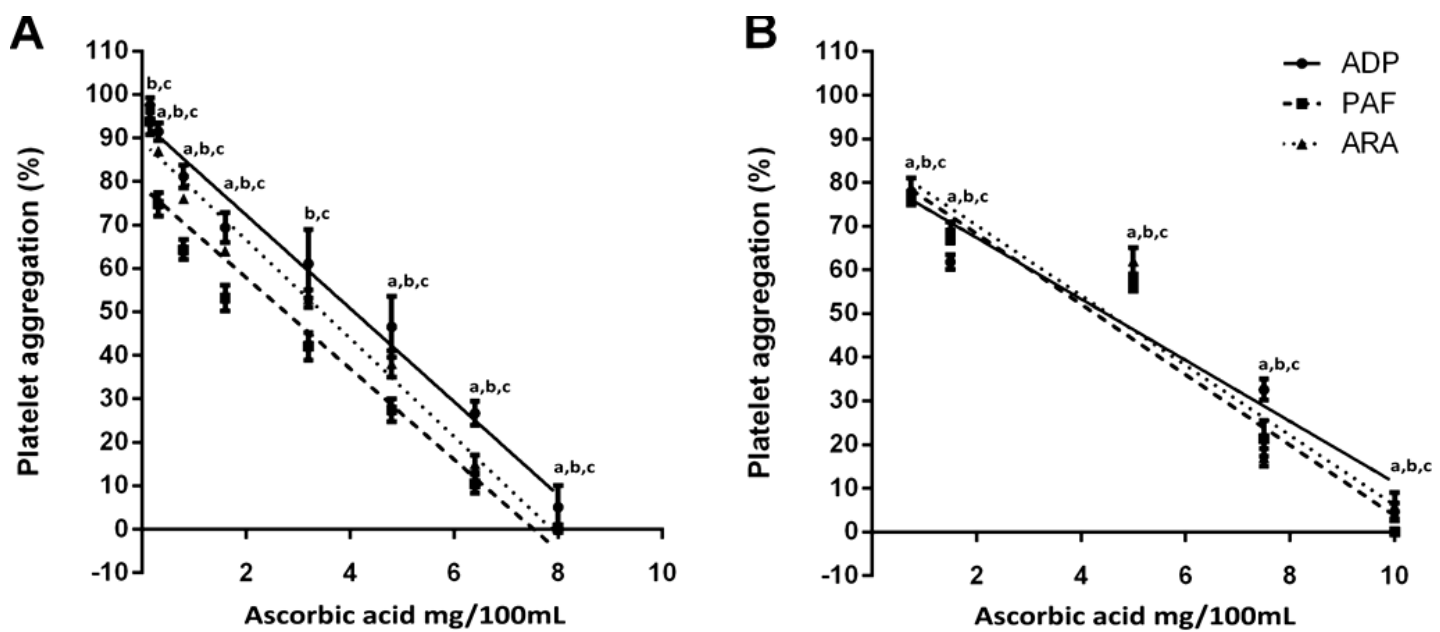

Fig. 2: Dose-dependent inhibition of platelet aggregation from ascorbic acid in (A) human and (B) washed rabbit platelets. Data are expressed as mean \pm S.D Each test was performed in triplicates. ADP, adenosine diphosphate; PAF, Platelet activating factor; ARA, arachidonic acid. Different letters indicate the significant differences $(\mathrm{p}<0.05)$ among the current and the exact previous (lower) dose. Symbol a for ADP, $b$ for PAF and $\mathrm{c}$ for ARA

\section{RESULTS}

Figure 1 shows the results of the ex vivo trials of the Capra prisca milk activity according to different doses $(0-20 \mu \mathrm{L})$ on platelet aggregation using ADP, PAF and ARA agonist. Both humans and washed rabbits platelets presented a dose dependent decrease of platelet aggregation. Platelet aggregation was completely inhibited at the highest doses tested $(20 \mu \mathrm{L})$. The $\mathrm{IC}_{50}$ values of ADP, PAF and ARA for human platelets were estimated at $14.3 \pm 1.0 \mu \mathrm{L}, 10.9 \pm 0.7 \mu \mathrm{L}$ and $12.5 \pm 0.5 \mu \mathrm{L}$, respectively. The $\mathrm{IC}_{50}$ values of $\mathrm{ADP}, \mathrm{PAF}$ and ARA were lower for washed rabbit platelets $(8.1 \pm 1.3 \mu \mathrm{L}, 8.9 \pm 0.7 \mu \mathrm{L}$ and $8.3 \pm 1.2 \mu \mathrm{L})$.

A dose-dependent decrease of platelet aggregation was also observed in human and washed rabbit platelets after incubation with increasing concentrations of ascorbic acid (Figure 2). Specifically, the $\mathrm{IC}_{50}$ values of $\mathrm{ADP}, \mathrm{PAF}$ and $\mathrm{ARA}$ were $4.1 \pm 0.7 \mathrm{mg} / 100 \mathrm{~mL}, 3.5 \pm 0.3 \mathrm{mg} / 100 \mathrm{~mL}$ and $4.2 \pm 0.3 \mathrm{mg} / 100 \mathrm{~mL}$ for human platelets and $4.6 \pm 0.3 \mathrm{mg} / 100 \mathrm{~mL}, 4.4 \pm 0.2 \mathrm{mg} / 100 \mathrm{~mL}$ and $4.8 \pm 0.4 \mathrm{mg} / 100 \mathrm{~mL}$ for washed rabbit platelets, respectively.
Platelet aggregation was completely inhibited at doses of $8 \mathrm{mg} / 100 \mathrm{~mL}$ for human platelets and $12 \mathrm{mg} / 100 \mathrm{~mL}$ for washed rabbit platelets.

The results of the ex vivo trials on the effects of Prisca goat milk and ascorbic acid on $\mathrm{TXB}_{2}$ production are shown in Figure 3. Inhibition of $\mathrm{TXB}_{2}$ production was similar for all three platelet agonist tested. Specifically, the $\mathrm{IC}_{50}$ values of $\mathrm{ADP}, \mathrm{PAF}$ and ARA for Prisca goat milk were $10.4 \pm 1 \mu \mathrm{L}, 9.5 \pm 0.7 \mu \mathrm{L}$ and $10.9 \pm 0.9 \mu \mathrm{L}$, respectively, whereas for ascorbic acid were $5.1 \pm 0.3 \mathrm{mg} / 100 \mathrm{~mL}, 4.7 \pm 0.2 \mathrm{mg} / 100 \mathrm{~mL}$ and $4.8 \pm 0.3$ $\mathrm{mg} / 100 \mathrm{~mL}$.

Linoleic acid failed to inhibit platelet aggregation in the range of values tested $(0.25-25 \mathrm{mg} / 100 \mathrm{~mL})$ (data not shown). On the other hand, linolenic acid showed a dose-dependent decrease of platelet aggregation of $\mathrm{ADP}, \mathrm{PAF}$ and $\mathrm{ARA}$ with $\mathrm{IC}_{50}$ values being $12.1 \pm 1.6 \mathrm{mg} / 100 \mathrm{~mL}, \quad 10.1 \pm 1.2 \mathrm{mg} / \mathrm{mL}$ and $9.1 \pm 1.4$ $\mathrm{mg} / 100 \mathrm{~mL}$, respectively. Complete platelet inhibition was observed at the highest doses tested (around $20 \mathrm{mg} / 100 \mathrm{~mL}$ ) (Figure 4). 

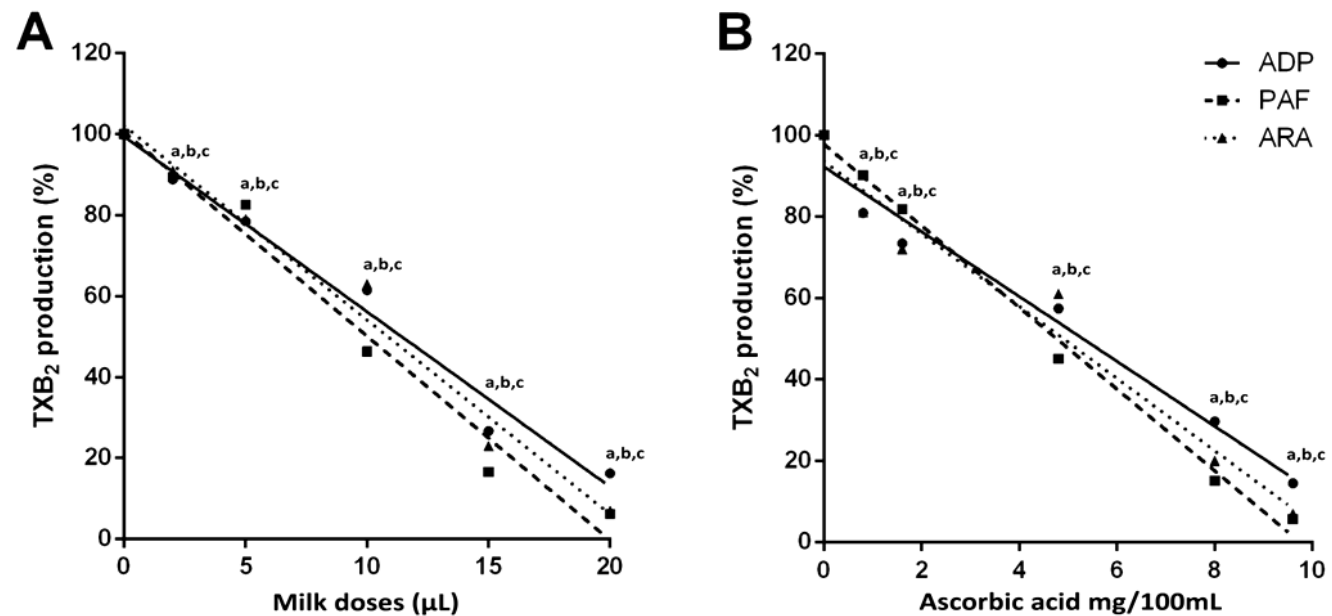

Fig. 3: Inhibition of $\mathrm{TXB}_{2}$ production from (A) Capra prisca milk and (B) ascorbic acid in human platelets. Data are expressed as mean \pm S.D. Each test was performed in triplicates. ADP, adenosine diphosphate; PAF, Platelet activating factor; ARA, arachidonic acid. Different letters indicate the significant differences $(\mathrm{p}<0.05)$ among the current and the exact previous (lower) dose. Symbol a for ADP, $\mathrm{b}$ for PAF and $\mathrm{c}$ for ARA

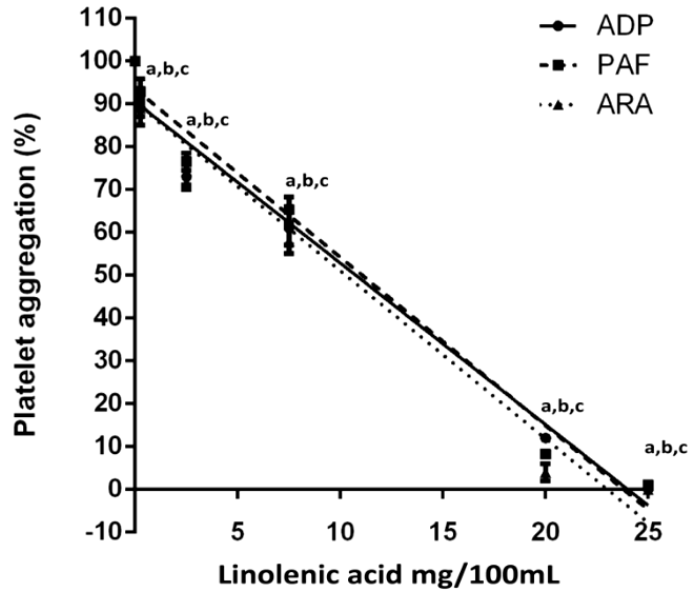

Fig. 4: Dose-dependent inhibition of platelet aggregation from linolenic acid in human platelets. Data are expressed as mean \pm S.D. Each test was performed in triplicates. ADP, adenosine diphosphate; PAF, Platelet activating factor; ARA, arachidonic acid. Different letters indicate the significant differences $(\mathrm{p}<0.05)$ among the current and the exact previous (lower) dose. Symbol a for ADP, $\mathrm{b}$ for PAF and $\mathrm{c}$ for ARA.

\section{DISCUSSION}

The experimental results showed that the milk of Prisca goat inhibited dose-dependently platelet aggregation in humans, as well as washed rabbit platelets. Goat's milk is a complex solution containing molecules of high molecular weight, as well as simpler molecules of smaller molecular weight. The literature indicates that casein's various fractions, as well as lactoferrin present enhanced antiplatelet properties, which partly might explain the inhibitory effect of Prisca goat's milk (Qian et al., 1995; Ruthefurd and Gill 2000; Manso et al., 2002; Hernandez-Ledesma et al., 2005a). On the other hand some simple antioxidant molecules such as ascorbic acid and various tocopherols exist in high concentrations in the milk of the indigenous Greek goat of Capra prisca (Kondyli et al., 2007) while it has been reported that these antioxidants can inhibit platelet aggregation (Karkabounas et al., 1996). It can be hypothesized that he ability of goat milk to inhibit platelet aggregation is the result of the individual activity of the components that make up the solution of goat milk. Thus, the antiplaletet properties of lactoferrin and casein are added up to those of ascorbic acid, tocopherols and linolenic acid. Recent research indicates that processing of selected milk proteins with antiplatelet properties resulted in an increase of their antioxidant capacity (Hernandez-Ledesma et al., 2005a; Hernandez-Ledesma et al., 2005b; Simos et al., 2011). Prisca goat's milk reduced the production of the thromboxane $\mathrm{B}_{2}$, an inactive metabolite of thromboxane $\mathrm{A}_{2}$. Thromboxane $\mathrm{A}_{2}$, a product of the arachidonic acid, stimulates the activation of new platelets as well as increases platelet aggregation. The majority of NSAIDs with antiplatelet properties inhibit the production of TXA $_{2}$ (Garret and Fitzgerald 1991). Ascorbic acid, tocopherols, various thiols, some flavonoids and polyphenols inhibit the enzymes of cyclooxygenase and lipoxygenase, who represent two of the most important enzymes for the arachidonic acid metabolites (Visioli et al., 2000; Nijveldt et al. 2001). An advantage of this study is that the doses of ascorbic acid, linoleic and linolenic acid used where in line with those found in native Greek goats. According to Kondyli et al., 2007 , mean content of ascorbic acid is $5.48 \pm 0.09 \mathrm{mg} / 100 \mathrm{~mL}$, well 
within the range we examined $(0.16-12.8 \mathrm{mg} / 100 \mathrm{~mL})$. Moreover, linoleic and linolenic acid content in native Greek goats was estimated at $559 \mu \mathrm{g} / 100 \mathrm{~mL}$ and $501 \mu \mathrm{g} / 100 \mathrm{~mL}$, respectively, and within the range we examined $(255-25500 \mu \mathrm{g} / 100 \mathrm{~mL})$. Washed rabbit platelets were used to exclude coagulation factors from the plasma in order to study cell to cell interaction.

\section{CONCLUSION}

Our data point to the conclusion that small molecules, such as ascorbic acid, play a dominant role in the inhibition of platelet aggregation, as well as on $\mathrm{TXB}_{2}$ production, while the two unsaturated fatty acids exert a mild inhibitory effect on this same action. The significance of the findings may lead to the classification of goat milk from certain indigenous breeds as functional food with health promoting properties leading to a broader acceptance from the consumers and to the development of farming systems aiming on the production of milk with superior nutritional characteristics.

\section{ACKNOWLEDGEMENTS}

The research is funded by the GSRT SYNERGASIA project GOSHOMICS (09SYN-23-990) and co-financed by the European Union and Greece Operational Program "Competitiveness and Entrepreneurship", European Regional Development Fund, NSFR 2007-2013.

\section{REFERENCES}

Alonso L, Fontecha J, Lozada L, Fraga MJ, Juarez M. Fatty acid composition of caprine milk: major, branched-chain, and trans fatty acids. J Dairy Sci, 1999; 82:878-84.

Amati L, Marzulli G, Marzulli M, Tafaro A, Jirillo F, Pugliese V, Martemucci G, D'Alessandro AG, Jirillo E. Donkey and goat milk intake and modulation of the human aged immune response. Curr Pharm Des, 2010; 16:864-69.

Attaie R, Richter RL. Size distribution of fat globules in goat milk. J Dairy Sci, 2000; 835:940-44.

D'Alessandro AG, Martemucci G, Jirillo E, Leo VD. Major whey proteins in donkey's milk: effect of season and lactation stage. Implications for potential dietary interventions in human diseases. Immunopharmacol Immunotoxicol, 2010; 1-7.

Evangelou A, Kalpouzos S, Karkabounas S, Liasko R, Nonni A, Stefanou D, Kallistratos G. Dose - related preventive and therapeutic effects of antioxidants-anticarcinogens on experimentally induced malignant tumors in Wistar rats. Cancer Lett, 1997; 115:105-11.

Evangelou AM, Malamas MP, Vezyraki P, Karkabounas SC. Is epinephrine-induced platelet aggregation autoregulated by its metabolic degradation products in vivo? In vivo, 1998; 12:321-25.

Garret A, Fitzgerald MD. Mechanism of platelet activation: Thromboxane A2 as an amplifying Signal for other agonists. Am J Cardiol, 1991; 68:118-48.

Hachelaf W, Boukhrelda M, Benbouabdellah M, Coquin P, Desjeux JF, Boudraa G, Louhami M (1993). Comparative digestibility of goat versus cow's milk fats in children with digestive malnutrition. Lait 1991; 73:593-99.

Hanlein GFW. Past, present and future perspectives of small ruminant dairy research. J Dairy Sci, 2001; 84:2097-115.

Hernandez-Ledesma B, Moralles B, Amigo L, Ramos M, Recio I. Identification of antioxidant and ACE - inhibitory peptides in fermented milk. J Sci Food Agric, 2005a; 85:1041-48.
Hernandez-Ledesma B, Dvalos A, Bartolom B, Amigo L. Preparation of antioxidant enzymatic hydrolysates from $\alpha$-lactalbumin and $\beta$-lactoglobulin. Identification of active peptides by HPLC-MS/MS. J Agric Food Chem, 2005b; 53:588-93.

Jirillo F, Martemucci G, D'Alessandro AG, Panaro MA, Cianciulli A, Superbo M, Jirillo E, Magrone T. Ability of goat milk to modulate healthy human peripheral blood lymphomonocyte and polymorphonuclear cell function in vitro effects and clinical implications. Curr Pharm Des, 2010; 16:870-76.

Kallistratos G, Evangelou A, Agnantis N, Fasske E, Karkabounas S, Donos A. Enhancement of the antineoplastic effect of anticarcinogens on benzo[a]pyrene-treated Wistar rats, in relation to their number and biological activity. Cancer Lett , 1994; 82:153-65.

Kallistratos G, Fasske E, Karkabounas S, Charalampopoulos K. 1988. Nutrition, Growth and Cancer. In: Tryfiates GP, Prasad KN, eds. New York: Prog Clin Biol Res AR. Liss, Inc, 377-89.

Karkabounas S, Sofis G, Evangelou A. Implication of free radicals in platelet aggregation: antiplatelet effects of free radical scavengers ex vivo. Epith Klin Farmacol Farmakokin, 1996; 10:84-91.

Kondyli E, Katsiari MC, Voutsinas LP. Variations of vitamin and mineral contents in raw goat milk of the indigenous Greek breed during lactation. Food Chem, 2007; 100:226-30.

Manso MA, Escudero C, Alijo M, Lopez-Fandino R. Platelet aggregation inhibitory activity of bovine, ovine, and caprin kappa-casein macropeptides and their tryptic hydrolysates. J Food Prot, 2002; 65:199296.

Martinez-Gonzalez MA, Sanchez-Villegas A. The emerging role of Mediterranean diets in cardiovascular epidemiology: monounsaturated fats, olive oil, red wine or the whole pattern? Eur J Epidemiol, 2004; 19:9-13.

Nijveldt RJ, van Nood E, van Hoorn DE, Boelens PG, van Norren K, van Leeuwen PA. Flavonoids: a review of probable mechanisms of action and potential applications. Am J Clin Nutr, 2001; 74:418-25

Pitsavos C, Panagiotakos DB, Tzima N, Chrysohoou C, Economou M, Zampelas A, Stefanadis C. Adherence to the Mediterranean diet is associated with total antioxidant capacity in healthy adults: the ATTICA study. Am J Clin Nutr, 2005; 82:694-99.

Qian ZY, Jolles P, Migliore-Samour D, Schoentgen F, Fiat AM. Isolation and characterization of sheep lactoferrin, an inhibitor of platelet aggregation and comparison with human lactoferrin. Biochim Biophys Acta, $1995 ; 1243: 25-32$.

Rutherfurd KJ, Gill HS. Peptides affecting coagulation. Br J Nutr, 2000; 84:S99-102.

Simos Y, Metsios A, Verginadis I, D’Alessandro AG, Loiudice $\mathrm{P}$, Jirillo $\mathrm{E}$ et al. Antioxidant and anti-platelet properties of milk from goat, donkey and cow: An in vitro, ex vivo and in vivo study. Int Dairy J, 2011; 21:901-6.

Tafaro A, Magrone T, Jirillo F, Martemucci G, D'Alessandro AG, Amati $\mathrm{L}$ et al.. Immunological properties of donkey's milk: its potential use in the prevention of atherosclerosis. Curr Pharm Des, 2007; 13:3711-17.

Visioli F, Borsani L, Galli C. Diet and prevention of coronary heart disease: the potential role of phytochemicals. Cardiovasc Res, 2000; 47:419-25

Willett WC, Sacks F, Trichopoulos A, Drescher G, Ferro-Luigi A, Helsing E, Trichopoulos D. Mediterranean diet pyramid: a cultural model for healthy eating. Am J Clin Nutr, 1995; 61:1402s-6s.

\section{How to cite this article:}

Peschos D, Simos YV, Fthenakis G, Zelovitis J, Boulaka A, Giouli M, Georgiou E, Ragos V, Tzora A, Tsangaris G, Evangelou A, Karkabounas S. Functional responses of human and rabbit platelets induced by milk from indigenous Greek dairy goats (Capra prisca). J App Pharm Sci, 2016; 6 (05): 063-067. 